\title{
PROJECT EARTH IS LEAVING BETA
}

\section{Get ready for a brand new experience!}

BY J.W. ALDEN

$\mathrm{D}$ ear Backers,

The beta test of Project Earth is finally over. We can't thank you enough for your patience and generosity during our crowdfunding period. But before we roll out Earth 1.0, there's a few things you should know.

First, the bad news: this update comes with a server wipe. Yes, we know you've poured time and effort into your 'lives' on Earth, and it's disappointing to lose your progress. Unfortunately, this can't be helped. We experimented with methods of porting existing avatars into the new version, but it brings a host of compatibility issues with our new character-creation system (more on that later). As a consolation, we're planning another exciting in-game 'End of the World' event, so you can go out with a bang.

Here are some big changes to expect in the new update:

NEW: Abuser Report System Every multiplayer experience comes with griefers and trolls. Unfortunately, the nature of Earth's gameplay makes it very difficult to tell when someone is being an asshole on purpose, but we've implemented a system that lets you flag an avatar for review. This notifies our mod team, who will examine the player's behaviour for signs of intentional griefing. Please don't abuse this feature! Only report an avatar if it exhibits unreasonable hostility that could not possibly be the result of normal 'human' development.

NEW: Advanced Career Paths A limited number of political and business leadership careers will open to the general playerbase. Previous builds allowed only members with mod privilege to take on certain leadership positions in-game, which allowed us to shape the progress of 'civilization' as we saw fit. We've listened to your feedback on this policy, and we're thrilled to open this aspect of the game to all players. We're also hoping this will address the 'conspiracy theory' phenomenon that became prevalent in previous builds.

NEW: Space Exploration Many of you were quite vocal when we curtailed the space race during our 'cold war' in-game event. At the time, we worried about the playerbase advancing past the capabilities of our current

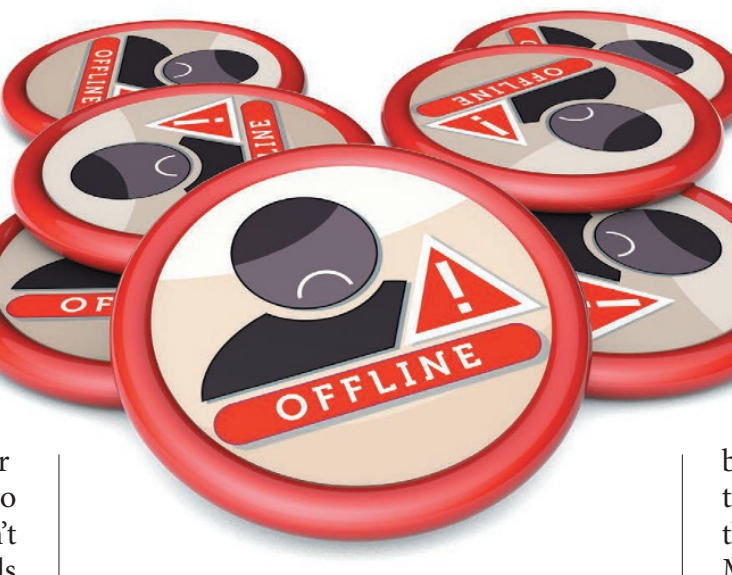

build, so we steered focus back towards Earth itself. Since then, we've been working hard on a new procedural engine for the cosmos, and now we're ready to roll it out. We hope this will revitalize many career questlines, including the astronaut path. Oh, and don't think we haven't heard your complaints about the light-speed barrier. These things take time.

FIXED: Character Imbalance We turned a blind eye to this for a while, because we knew a fix would cause waves, no matter how we approached it. But after long deliberation, we've given the character-creation suite an overhaul. A proprietary algorithm now determines your character's congenital traits, including things such as gender, race and sexual orientation. Any trait your avatar is 'born' with will be free of manipulation from players or mods. We know this might upset those of you who feel these traits are a matter of player choice, but we believe this is the more realistic approach. An increase in diversity will only enhance our experience on Earth. Plus, the inexplicable dominance of the 'straight white male' template kept crashing parts of the system.

FIXED: Dreams We've finally isolated the cause of the 'dream' phenomenon, in which an avatar retains glimpses of the player's real-world memories upon waking from logout status. Some team members argued that we should make this bug a supported feature, owing to the impact of dreams on art and culture in Earth 0.91. In the end, we're not comfortable with the risk

$\rightarrow$ NATURE.COM

Follow Futures: @ @ NatureFutures f go.nature.com/mtoodm involved. Although it hasn't happened yet, this dream glitch could lead to avatars realizing that their 'lives' are a game. We're not entirely sure what would happen if this occurred, but we're looking to avoid the sudden emergence of a secret resistance group working towards exposing the simulation, so we decided to remove them.

FIXED: History Leak There's been discussion on the forums about a 'history leak' phenomenon, in which various myths, legends and religious tales seem to reflect previous builds of Earth. For instance, the Greek pantheon resembles the superuser avatars that the development team used in our alpha test. Many flood myths bear a strong resemblance to the 'End of the World' event from our first playable build. While working on the dream bug, we discovered a crucial link between these two phenomena, which helped us to iron this one out. Sorry, but your old avatar won't be worshipped as a messiah in Earth 1.0.

As this marks our official release, we anticipate a large influx of new players. We've set up a special section of the forums for firsttimers. Please consider paying it a visit and offering some advice to the noobs. Remember how disorienting your first trip to Earth was (especially if you installed the 'childhood' DLC expansion).

The new 'End of the World' event is scheduled for 21 December. We expect a doomsday cult or two to arise before then, as some of you will unwittingly communicate this date to your avatars in dreams. For this reason, we're keeping the nature of the apocalypse a secret until the end is upon you. Rest assured we've come up with something exciting and different this time around. No floods, plagues or supervolcanoes. We'll give you one hint: watch the sky.

On behalf of everyone here at Blue Marble, we'd like to thank our backers and beta testers. Our little world couldn't have made it this far without you, and we hope that you're all permanent residents. Earth 1.0 is only the beginning!

\section{E. D. Amun}

Development lead, Project Earth

Blue Marble Games, Subsidiary of Ogdoad Entertainment. $\square$

J. W. Alden is a graduate of Odyssey Writing Workshop and a 1st Place Writers of the Future winner. He lives in Florida with his wife, Allison. Find him at www. AuthorAlden.com. 